\title{
Characteristics of Anomalous Radio Propagation before and after the 2011 Tohoku-Oki Earthquake as Seen by Oblique Ionograms
}

\author{
Kiyoshi Igarashi, Toshio Tsuchiya, Ken Umeno \\ Department of Applied Mathematics and Physics, Graduate School of Informatics, Kyoto University, Kyoto, Japan \\ Email: igarashi.kiyoshi.7e@kyoto-u.ac.jp, tsuchiya.toshio.3s@kyoto-u.ac.jp, umeno.ken.8z@kyoto-u.ac.jp
}

How to cite this paper: Igarashi, K., Tsuchiya, T. and Umeno, K. (2020) Characteristics of Anomalous Radio Propagation before and after the 2011 Tohoku-Oki Earthquake as Seen by Oblique Ionograms. Open Journal of Earthquake Research, 9, 100-112.

https://doi.org/10.4236/ojer.2020.92007

Received: January 21, 2020

Accepted: March 9, 2020

Published: March 12, 2020

Copyright $\odot 2020$ by author(s) and Scientific Research Publishing Inc. This work is licensed under the Creative Commons Attribution International License (CC BY 4.0).

http://creativecommons.org/licenses/by/4.0/

\begin{abstract}
The characteristics of anomalous radio propagation in the frequency 1 - 30 $\mathrm{MHz}$ before and after the 2011 Tohoku-Oki earthquake are firstly revealed by using oblique ionograms for the pass from Wakkanai to Kokubunji which is closest to the epicenter. An oblique ionogram with a wavy-shape-trace was observed at 06:30 UTC on 11 March 2011 after the 2011 Tohoku-Oki earthquake. The velocity of northward-propagating disturbance caused this wavy-shape-trace is estimated to be $130 \mathrm{~m} / \mathrm{s}$. This wave-shape-trace shows very clear signature appearing in the oblique ionograms as the characteristic of strong ionospheric disturbances triggered by the earthquake. An oblique ionogram with a steep slopy-shape-trace was observed at 04:45 UTC on 11 March 2011 one hour before the 2011 Tohoku-Oki earthquake. This slopy-shape-trace is investigated as the signatures of preseismic ionospheric anomaly. This anomalous oblique ionogram with a slopy-shape-trace is examined with the slope ratio of virtual height to sweep-frequency, and the difference between monthly median foF 2 and hourly value foF2 at Wakkanai and Kokubunji. These features appearing in oblique ionograms suggest that it is useful for studying the signatures of preseismic ionospheric anomaly.
\end{abstract}

\section{Keywords}

Ionospheric Disturbances, Oblique Ionogram, Anomalous Radio Propagation, Atmospheric Gravity Waves

\section{Introduction}

The characteristics of strong ionospheric disturbances associated with the 2011 
Tohoku-Oki earthquake (M9.0) occurring at 0546:18 UTC on 11 March 2011 in Japan have been analyzed by the high-resolution GPS total electron content (TEC) observation of GPS receiver network, GEONET [1] [2] [3] [4], the ionograms of four ionosonde stations in Japan [5] [6], and the SuperDARN Hokkaido HF radar [7] [8]. The initial ionospheric disturbances observed by GPS TEC measurements showed small impulsive TEC enhancements about $7 \mathrm{~min}$ after the earthquake onset and concentric waves appearing to propagate in the radial direction with a velocity $138-3457 \mathrm{~m} / \mathrm{s}$ [3]. Ionospheric disturbances were detected at 06:00 UTC at four ionosonde stations in Japan and an irregular distorted echo trace was observed at Kokubunji closest to the epicenter and $400 \mathrm{~km}$ away [5] [6]. The SuperDARN Hokkaido HF radar observed northward-propagating disturbances $(343-136 \mathrm{~m} / \mathrm{s}$ ) due to atmospheric gravity waves (AGWs) exiting near the epicenter after the passage of the $6.7-1.8 \mathrm{~km} / \mathrm{s}$ waves [8]. The preseismic ionospheric anomalies detected before the earthquake are investigated with a method of CoRelation Analysis (CRA) from phase delays of signals observed at densely arranged ground-based stations of Global Navigation Satellite Systems for the 2011 Tohoku-Oki earthquake [9], the 2016 Kumamoto earthquake [10] and the 2016 Taiwan earthquake [11]. The preseismic ionospheric electron enhancements before large earthquake have been reported for short-term earthquake prediction [12] [13] [14]. Preseismic ionospheric anomalies in Taiwan were examined to reveal that the ionospheric TEC and NmF2 surrounding the epicenters of the events decreased abnormally within 5 days before large earthquakes [15] [16] [17] [18].

Ionospheric disturbances associated with the 2011 Tohoku-Oki earthquake have been studied in many excellent papers. The oblique ionospheric sounding data, namely oblique ionograms have not been previously examined for studying the characteristics of anomalous radio propagation associated with the super strong earthquake. It is new to focus on both before and after the strong earthquake, and to study the ionospheric disturbances of strong earthquake as seen by oblique ionograms. In this paper the characteristics of anomalous radio propagation in the frequency $1-30 \mathrm{MHz}$ before and after the 2011 Tohoku-Oki earthquake are investigated by oblique ionograms obtained for the pass of relatively medium distance $1068 \mathrm{~km}$ between Wakkanai and Kokubunji which is closest to the epicenter. This paper focuses on the trace shape and trace distortions around the maximum observable frequency in the oblique ionogram trace which shows a signature of the anomalous radio propagation. Vertical and oblique ionospheric sounding system in Japan is shown briefly. Then the characteristics appearing in oblique ionograms before and after the 2011 Tohoku-Oki earthquake are shown and discussed in three types of oblique ionogram traces.

\section{Vertical and Oblique Ionospheric Sounding}

Figure 1 shows a location map of ionosonde stations in Japan. Four ionosonde stations are located at Wakkanai/Sarobetsu $\left(45.16^{\circ} \mathrm{N}, 141.75^{\circ} \mathrm{E}\right)$, Kokubunji 


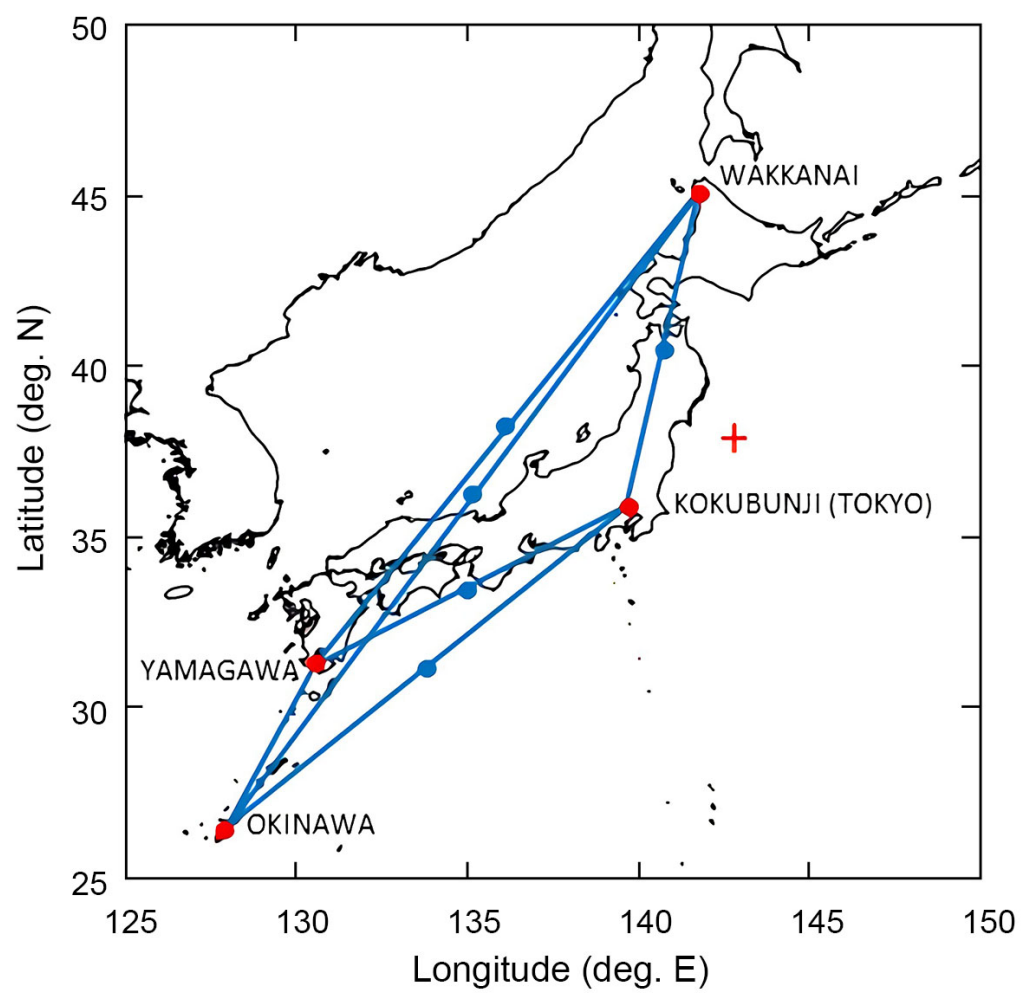

Figure 1. Ionosonde stations in Japan are shown as four red dots. Blue dots represent middle points between transmitting ionosonde stations and receiving ionosonde stations. The epicenter of mainshock at 0546:18 UTC on 11 March 2011 is indicated by a red plus sign.

$\left(35.71^{\circ} \mathrm{N}, 139.49^{\circ} \mathrm{E}\right)$, Yamagawa $\left(31.2^{\circ} \mathrm{N}, 130.62^{\circ} \mathrm{E}\right)$, and Okinawa/Ogimi $\left(26.68^{\circ} \mathrm{N}, 128.15^{\circ} \mathrm{E}\right)$. The four ionosonde stations are regularly operated with a small time shift from the nominal time stamp every quarter hour by $-105,-30$, +45 , and $+120 \mathrm{~s}$ for Wakkanai, Kokubunji, Yamagawa, and Okinawa, respectively [5]. Therefore both of vertical and oblique ionograms are available at approximately same time. The sweep-frequency rate of these four ionosondes is 2 $\mathrm{MHz} / \mathrm{s}$. The transmitter and receiver frequency of ionosonde are varied together over a range of $1-30 \mathrm{MHz}$. In this paper we used oblique ionograms obtained for a medium distance $1068 \mathrm{~km}$ path between Wakkanai and Kokubunji which is closest to the epicenter of the 2011 Tohoku-Oki earthquake $\left(38.10^{\circ} \mathrm{N}, 142.86^{\circ} \mathrm{E}\right)$.

Figure 2 shows the geometry of the one-hop F2 propagation for the high-angle ray path and low-angle ray path as the oblique ionospheric sounding, and the vertical ionospheric sounding at Wakkanai and Kokubunji. The sweep-frequency ionospheric sounding technique with High-frequency $(3-30 \mathrm{MHz}$ ) radio waves was developed to probe the vertical structure of the ionosphere and to study the ionospheric dynamics. Ionosondes are operated routinely for the ionospheric weather monitoring, providing ionospheric variations in near real-time and from a global network of observatories. It is also possible to investigate the characteristics of anomalous radio propagation by the oblique ionospheric sounding method receiving sweep-frequency pulsed radio waves from other vertical ionospheric 


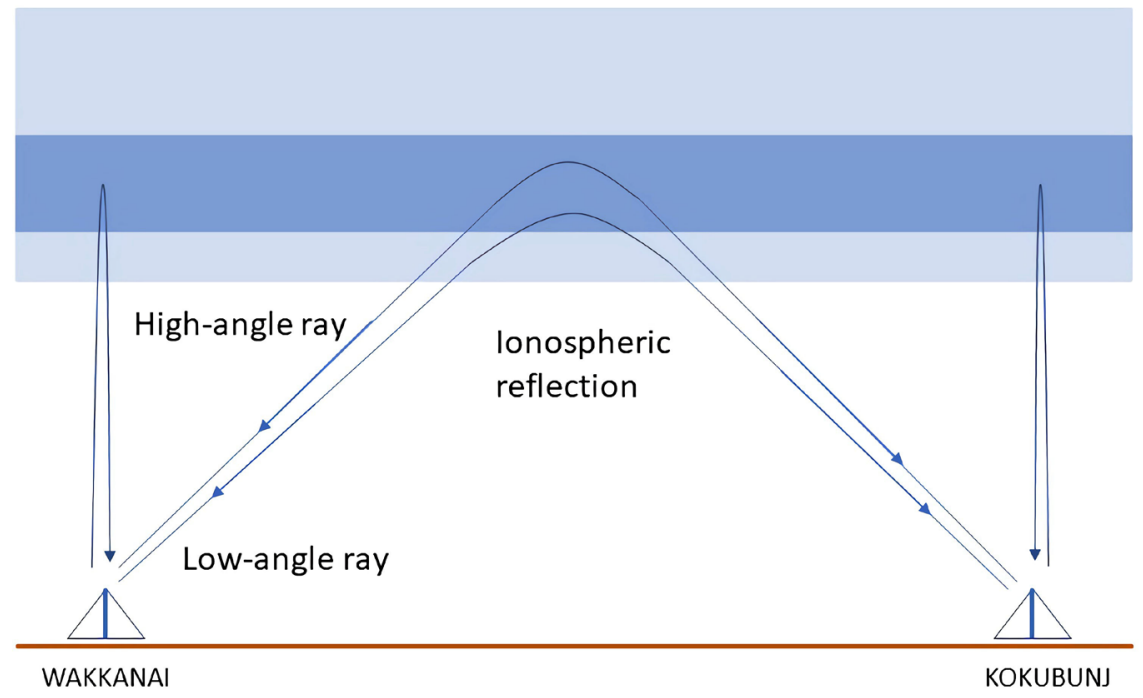

Figure 2. Geometry for vertical ionospheric sounding at Wakkanai and Kokubunji, and oblique ionospheric sounding between Wakkanai and Kokubunji which is a relatively medium distance of $1068 \mathrm{~km}$.

sounding stations. The oblique ionograms obtained with oblique ionospheric soundings are possible to reveal the ionospheric variations along the propagation pass over the ocean above tectonic plates in Japan.

\section{Observation Results and Discussion}

\subsection{Characteristics of Oblique Ionograms after the 2011 Tohoku-Oki Earthquake}

Figures 3(a)-(d) show four successive oblique ionograms every 15 minutes from 05:45 UTC to 06:30 UTC taken at Kokubunji for the pass from Wakkanai to Kokubunji which is closest to the epicenter. The pass from Wakkanai to Kokubunji is a relatively medium distance of $1068 \mathrm{~km}$. The earthquake timing of main shock (M9.0), aftershock (M7.4), aftershock (M7.7) and aftershock (M7.5) are indicated in the time axis of Figure 3. Four oblique ionograms in Figure 3 are enlarged in Figure 4. One hop F2 trace is confirmed with a weak Es echo. These oblique ionograms show the ordinary and extraordinary traces, and high- and low-angle traces. The $\mathrm{F} 2 \mathrm{MOF}(\mathrm{o})$ is called as the maximum observed frequency of the ordinary wave that is reflected once at the F2 layer. The F2MOF(o) of the oblique ionogram at 05:45 UTC just before the main shock of the 2011 Tohoku-Oki Earthquake is $16.26 \mathrm{MHz}$. We found anomalous oblique ionogram for the pass from Wakkanai to Kokubunji at 06:30 UTC in Figure 4(d). Figure 5 shows an enlarged oblique ionogram of Figure 4(d). The "nose" of this oblique ionogram is a wavy-shape-trace and the $\mathrm{F} 2 \mathrm{MOF}(\mathrm{o})$ is $14.86 \mathrm{MHz}$. If this wavy-shape-trace is caused by strong ionospheric disturbances induced by the 2011 Tohoku-Oki earthquake on 11 March 2011, a propagation velocity of AGWs could be estimated. The estimated distance between the epicenter of earthquake and the ground below the ionospheric reflection point of oblique 
WAKKANAI $\rightarrow$ KOKUBUNJI Oblique lonograms

(a) 05:45 UTC

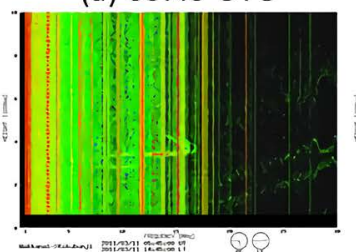

(b) 06:00 UTC

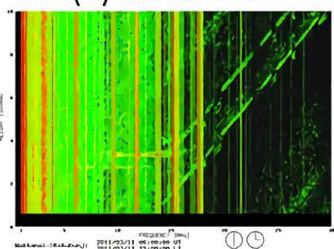

(c) 06:15 UTC

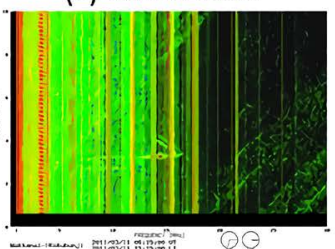

(d) 06:30 UTC

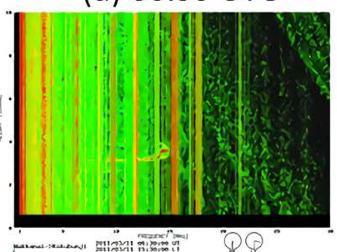

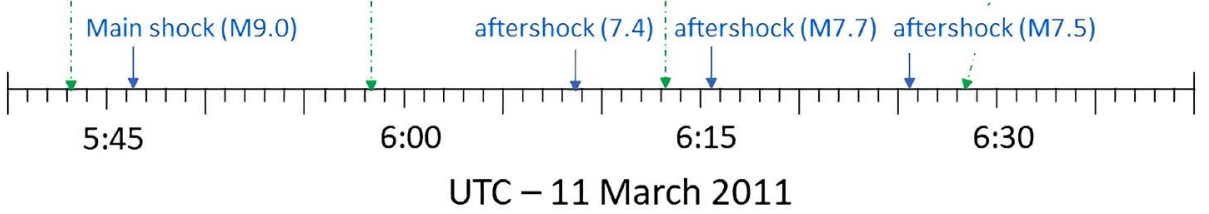

Figure 3. Four oblique ionograms every 15 minutes from 05:45 UTC to 06:30 UTC for the pass from Wakkanai to Kokubunji which is closest to the epicenter. The time marks of main shock and after shock, and transmitting time marks of Wakkanai ionosonde are indicated by arrows every $15 \mathrm{~min}$ on the time axis. The observation time stamps are shown at the top of the oblique ionograms. A small time shift is $-105 \mathrm{~s}$ for the ionosonde at Wakkanai.
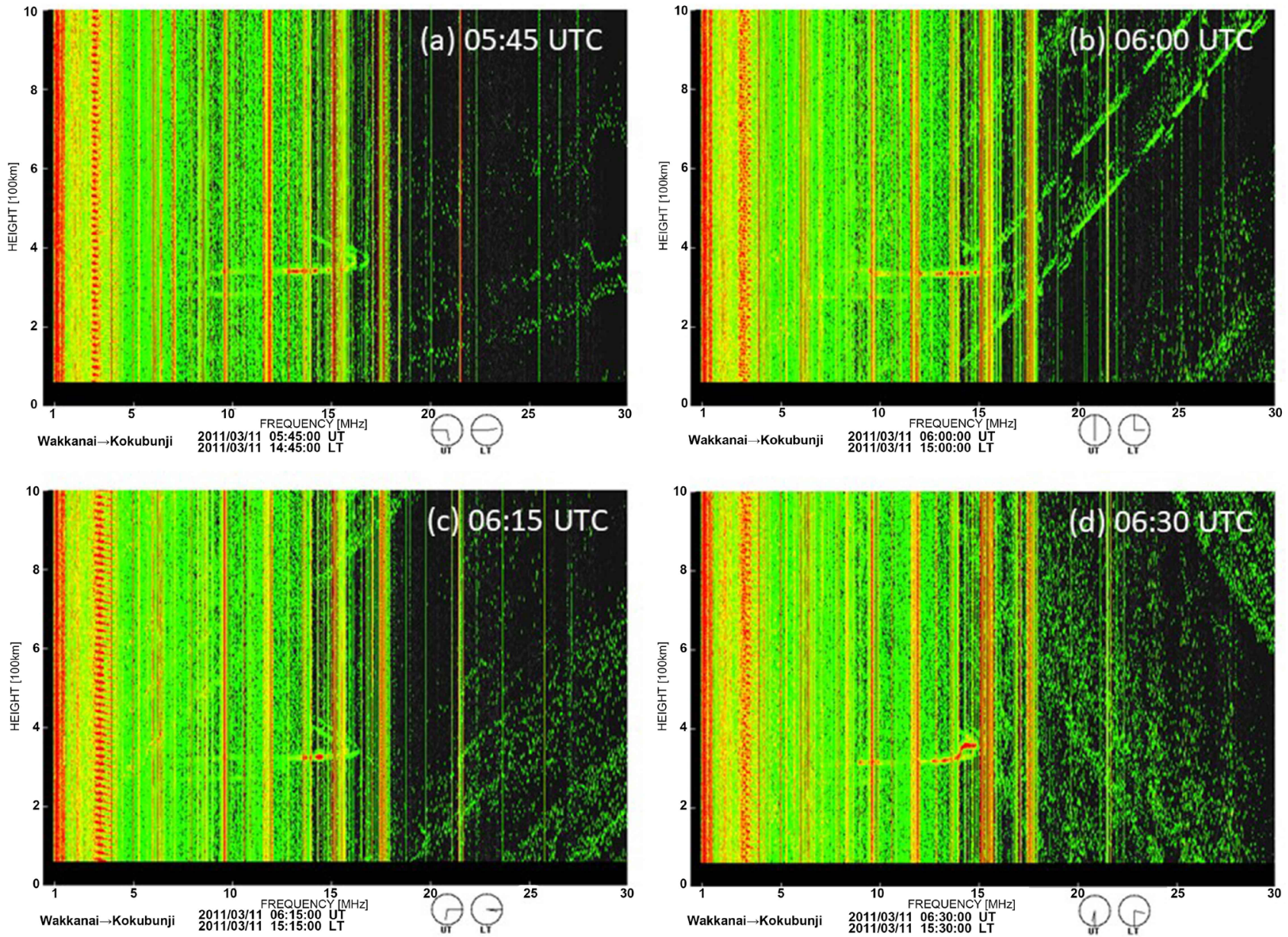

Figure 4. Four successive oblique ionograms at 05:45 UTC on 11 March 2011 just before the earthquake, at 06:00 UTC, 06:15 UTC and 06:30 UTC on 11 March 2011 after the 2011 Tohoku-Oki earthquake. The vertical axis is a virtual height 0 - $1000 \mathrm{~km}$ and the horizontal axis is a sweep frequency $1-30 \mathrm{MHz}$. 


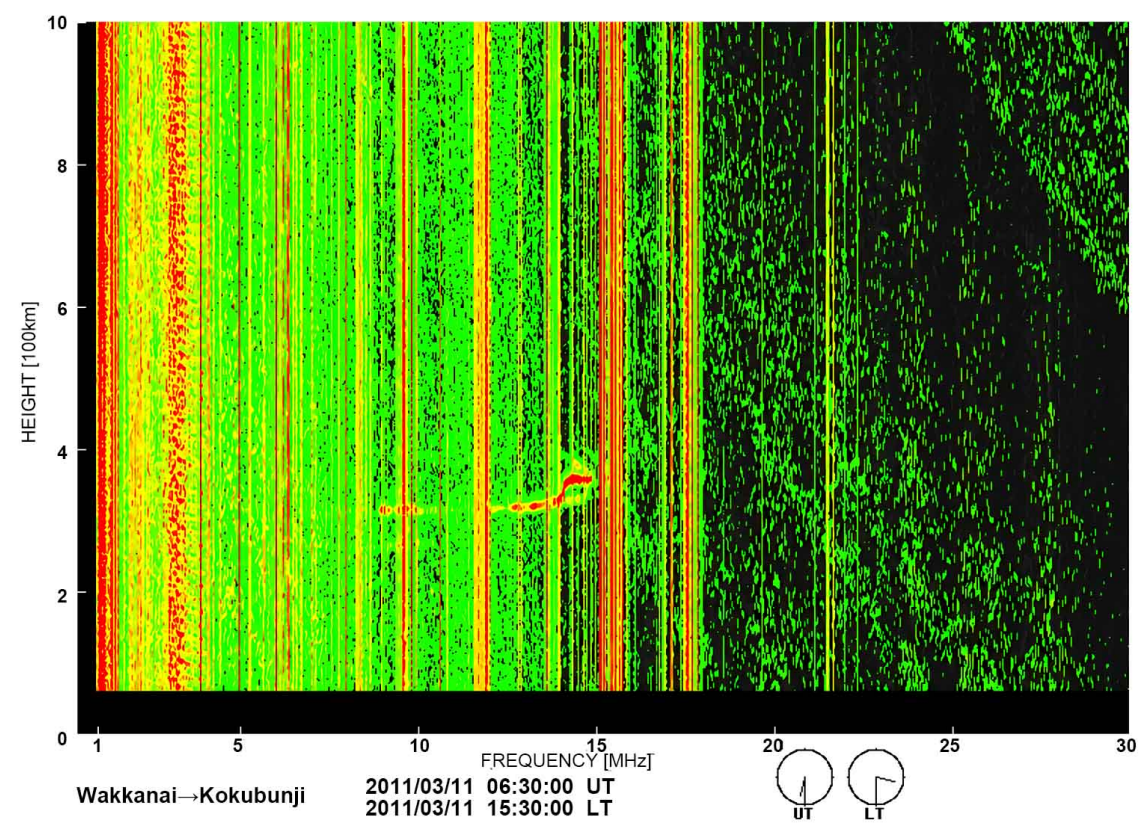

Figure 5. Anomalous oblique ionogram with a wavy-shape-trace taken at Kokubunji at 06:30 UTC on 11 March 2011 for the pass from Wakkanai to Kokubunji which is closest to the epicenter.

sounding echo is $328 \mathrm{~km}$. This propagation velocity is obtained by dividing the distance from the epicenter to the reflection point by the delay time between the occurrence time of the main shock and the observation time of the wave-shape-trace. The northward propagation velocity of the ionospheric disturbance caused the wavy-shape-trace in Figure 5 is estimated to be $130 \mathrm{~m} / \mathrm{s}$. Ogawa et al. [8] investigated the HF radar observed northward-propagating disturbances due to AGWs perhaps exited near the epicenter. The northward propagation velocities were estimated to be $343-136 \mathrm{~m} / \mathrm{s}$ by the propagation velocity of the enhanced echo region during 06:30-08:00 UTC on 11 March 2011. Tsugawa et al. [3] revealed ionospheric disturbances after the 2011 Tohoku-Oki earthquake with the high-resolution GPS-TEC observation in Japan that medium-scale concentric waves with a slower propagation velocity $(138-423 \mathrm{~m} / \mathrm{s}$ ) and less dissipation propagated in a radial direction following the large-scale waves after 06:15 UT. The propagation velocity estimated by oblique ionogram is slightly slower but similar speed with the HF radar observed northward-propagating disturbances and the GPS-TEC observed medium-scale concentric waves. Therefore a wave-shape-trace of the oblique ionogram is consistent with the observation results which are considered due to AGWs excited near the epicenter. Maruyama et al. [5] [6] observed multiple-cusp-type trace indicating extra stratification in the ionograms taken from 06:00 UTC to 16:45 UTC at Wakkanai and Yamagawa, which are 790 and $1355 \mathrm{~km}$ away from the epicenter.

We found that the characteristic of strong disturbances triggered by the earthquake shows very clear signature of wavy-shape-trace appeared in the ob- 
lique ionogram. Our result about the wavy-shape-trace seen by oblique ionogram for the pass from Wakkanai to Kokubunji is consistent with the existing physical theory of postseismic phenomena to cause due to AGWs exited near the epicenter according to the above analysis.

\subsection{Characteristics of Oblique Ionograms before the 2011 Tohoku-Oki Earthquake}

The oblique ionograms within 2 hours before the 2011 Tohoku-Oki earthquake are shown in Figures 6(a)-(d) which are four successive oblique ionograms every 15 minutes from 04:30 UTC to 05:15 UTC taken at Kokubunji for the pass from Wakkanai to Kokubunji. The graph of Hi-net 100-trace continuous waveform images is shown below Figure 6. The Hi-net is an abbreviation for High Sensitivity Seismograph Network Japan operated by National Research Institute for Earth Science and Disaster Resilient. Four oblique ionograms in Figure 6 are enlarged in Figure 7. The "nose" of oblique ionograms is a parabolic-shape-trace except the oblique ionogram of 04:45 UTC. Figure 8 shows this anomalous oblique ionogram. The characteristics of oblique ionogram at 04:45 UTC show a slopy-shape-trace. F2MOF(o) of this slopy-shape-trace is $14.98 \mathrm{MHz}$. The start and end coordinates (frequency, virtual height) of this slope-shape-trace are $(14.98 \mathrm{MHz}, 382 \mathrm{~km})$ and $(13.26 \mathrm{MHz}, 340 \mathrm{~km})$ respectively. The slope ratio of virtual height h' to sweep-frequency $\mathrm{f}\left(\Delta \mathrm{h}^{\prime} / \Delta \mathrm{f}\right)$ is about $25(\mathrm{~km} / \mathrm{MHz})$.

The appearance frequency of such a slopy-shape-trace in the oblique ionograms was checked for the oblique ionograms of the pass from Wakkanai to Kokubunji at the same local time of 13:45 JST (04:45 UTC) for two months before

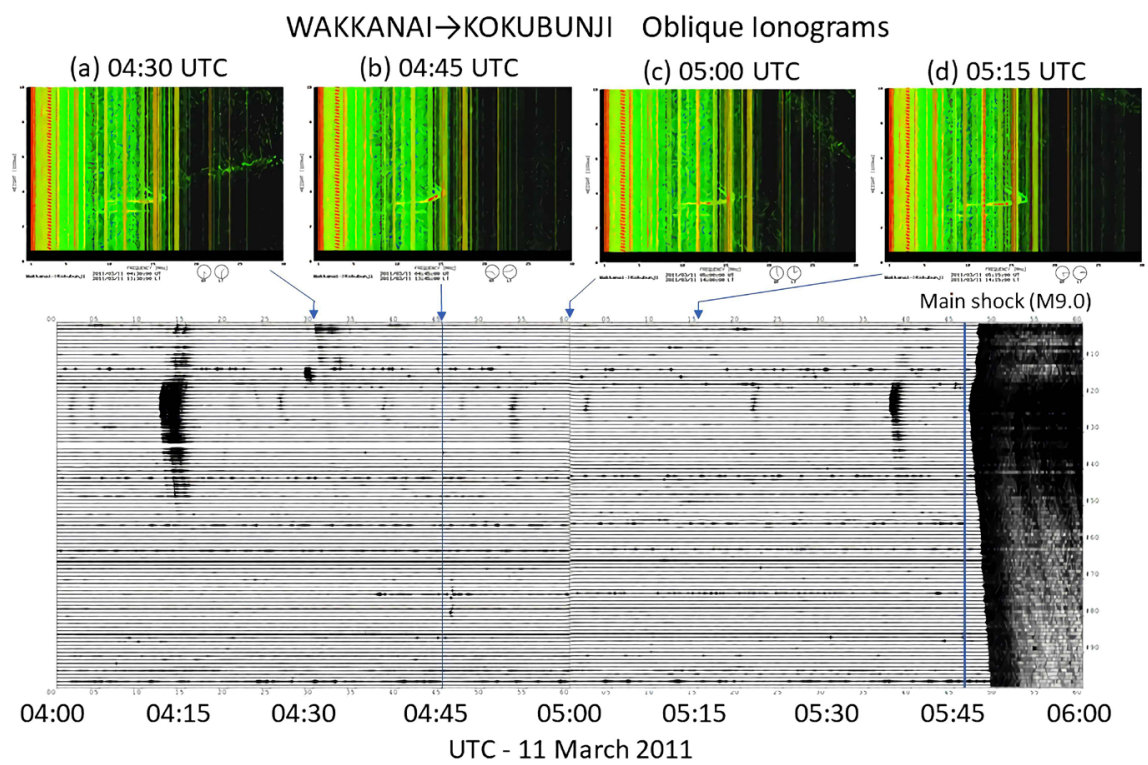

Figure 6. Four oblique ionograms every 15 minutes from 04:30 UTC to 05:15 UTC for the pass from Wakkanai to Kokubunji which is closest to the epicenter. A small time shift is $-105 \mathrm{~s}$ for the ionosonde at Wakkanai. The bottom of Figure 5 shows Hi-net 100-trace continuous waveform images. 

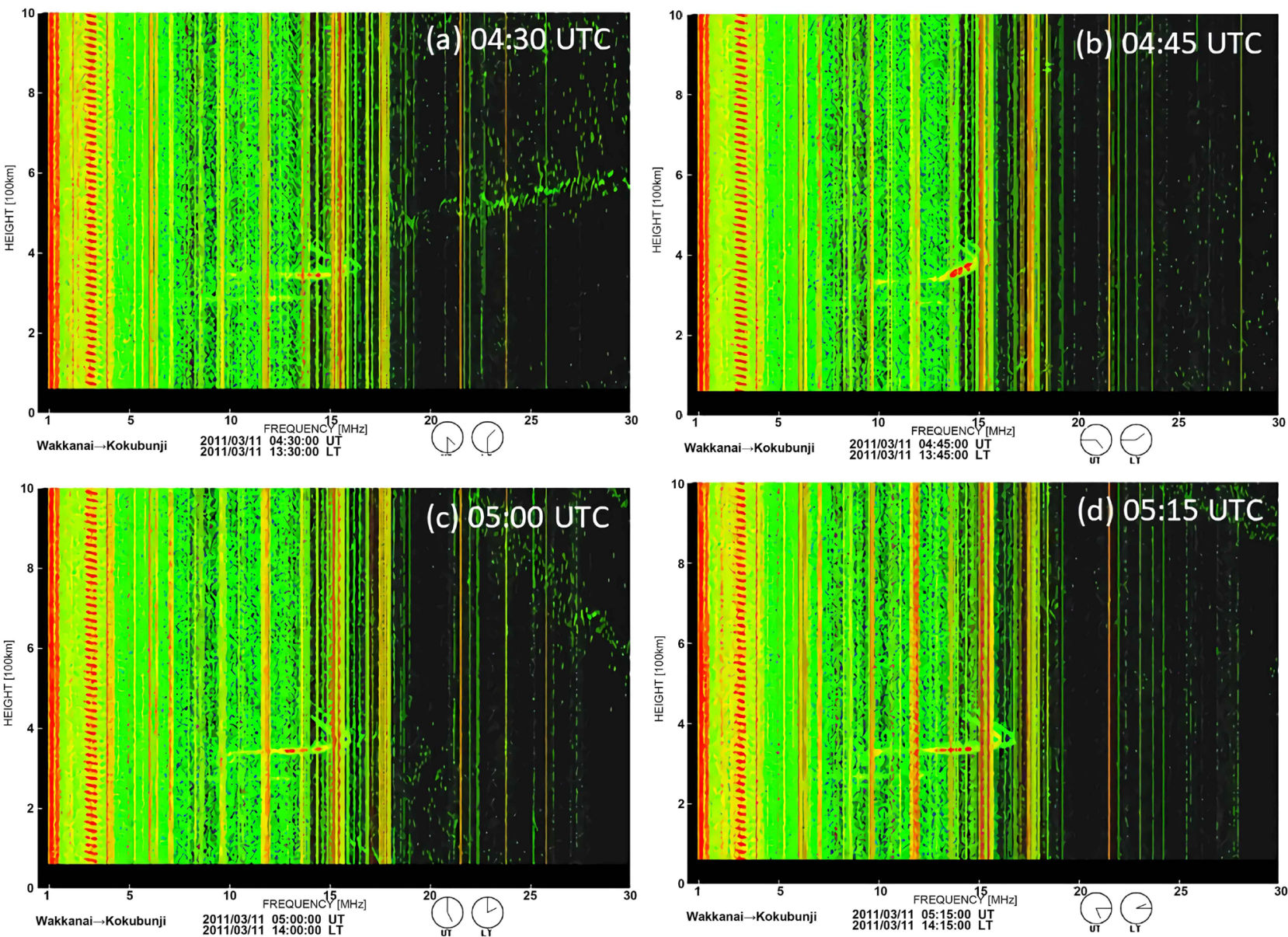

Figure 7. Four successive oblique ionograms at 04:30 UTC, 05:00 UTC, 05:15 UTC and 05:30 UTC on 11 March 2011 before the 2011 Tohoku-Oki earthquake. The vertical and horizontal axes are the same as Figure 4.

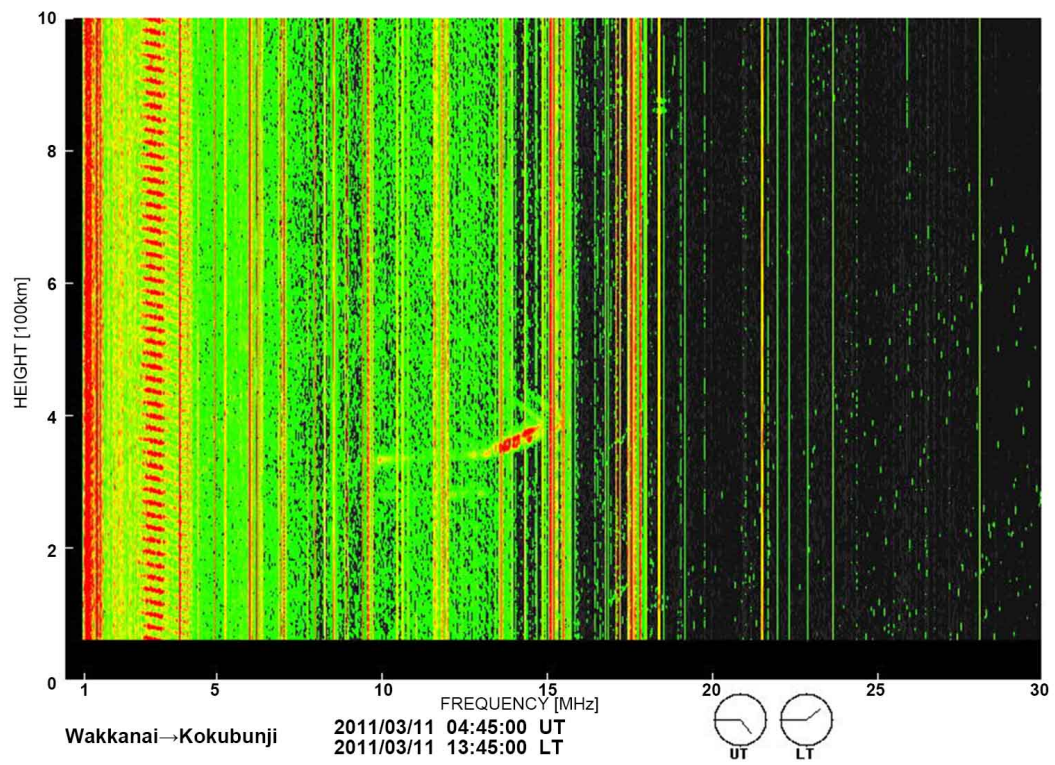

Figure 8. Anomalous oblique ionogram with steep slopy-shape-trace taken at Kokubunji at 04:45 UTC on 11 March 2011 for the pass from Wakkanai to Kokubunji which is closest to the epicenter. 
the earthquake. There is no evidence of this steep slopy-shape-trace type except the oblique ionogram at 04:45 UTC before one hour of the 2011 Tohoku-Oki earthquake. Shuanggen J. et al. [19] showed the geomagnetic index and solar radio flux variations in March 2011. The Dst, AE and Ap index indicated some disturbances during the Tohoku-Oki earthquake. In order to check the ionospheric variations the monthly median of foF2 and the hourly value of foF2 on 11 March 2011 are presented for Wakkanai and Kokubunji in Figure 9. The hourly values of foF 2 are manually scaled with reading accuracy $0.1 \mathrm{MHz}$ which has been established internationally [20]. The difference between the monthly median of foF2 and the hourly value of foF 2 is from $+0.1 \mathrm{MHz}$ to $+1.3 \mathrm{MHz}$ for Wakkanai and from $+0.4 \mathrm{MHz}$ to $+1.8 \mathrm{MHz}$ for Kokubunji in the period from 4:00 UTC to 8:00 UTC on 11 March 2011. The difference between the monthly median of foF 2 and the hourly value of foF 2 is $+0.85 \mathrm{MHz}$ as interpolated value between 04:00 UTC and 05:00 UTC at 04:45 UTC which the anomalous slopy-shape-trace was confirmed for the oblique ionogram of the pass from Wakkanai to Kokubunji. Figure 10 shows the conceptual diagrams for the "nose" of

11 March 2011
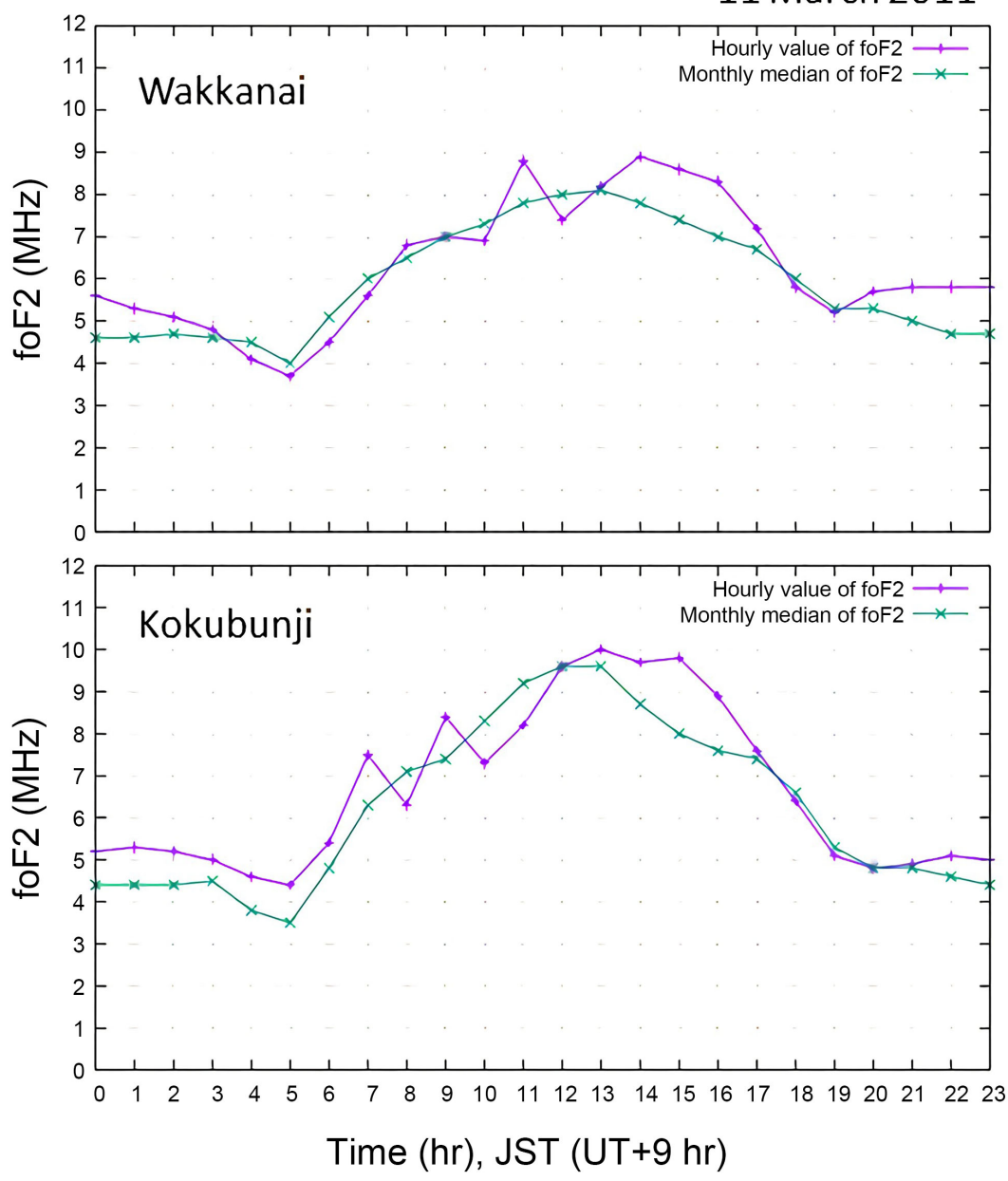

Figure 9. Variations of hourly value foF2 (purple line) and monthly median foF2 (green line) at Wakkanai (upper panel) and Kokubunji (lower panel) on 11 March 2011. 


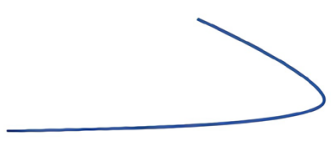

(a)

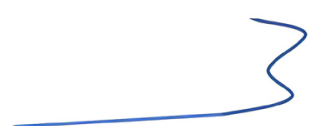

(b)

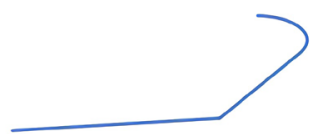

(c)

Figure 10. Conceptual diagrams for the "nose" of the relatively medium distance oblique ionograms which were observed before and after the 2011 Tohoku-Oki earthquake. (a) Parabolic-shape-trace, (b) Wavy-shape-trace, and (c) Slopy-shape-trace.

the relatively medium distance oblique ionograms which were observed before and after the 2011 Tohoku-Oki earthquake. Normal oblique ionogram in the daytime shows (a) parabolic-shape-trace. Anomalous oblique ionograms after and before the earthquake show (b) wavy-shape-trace and (c) slopy-shape-trace respectively. Point-to-point oblique ionograms are traces of group path versus frequency for oblique HF radio propagation between two fixed points separated by some distance. The "nose" of oblique ionogram with the parabolic-shape-trace shows two propagation path of low angle ray and high angle ray at the same frequency between two fixed points of Wakkanai and Kokubunji as shown in Figure 2. The slopy-shape-trace is considered a signature under some disturbed ionospheric conditions [21] [22].

The wavy-shape-trace with trace distortions is considered a signature of medium-scale-traveling ionospheric disturbances due to AGWs [23] [24] [25].

\section{Summary and Conclusions}

We have investigated the characteristics of anomalous HF propagation before and after the 2011 Tohoku-Oki earthquake that appeared in the oblique ionograms for the pass of relatively medium distance $1068 \mathrm{~km}$ from Wakkanai to Kokubunji. An oblique ionogram with a wavy-shape-trace was observed at 06:30 UTC on 11 March 2011 after the 2011 Tohoku-Oki earthquake. This wavy-shape-trace of oblique ionogram is considered northward-propagating disturbances due to AGWs excited near the epicenter. The propagation velocity of this disturbance is estimated to be $130 \mathrm{~m} / \mathrm{s}$. We found that the characteristic of strong ionospheric disturbances triggered by the earthquake appearing in the oblique ionogram shows very clear signature of the wave-shape-trace.

An oblique ionogram with a slopy-shape-trace was observed at 04:45 UTC on 11 March 2011 one hour before the 2011 Tohoku-Oki earthquake. The slope ratio of virtual height h' to sweep-frequency $f\left(\Delta h^{\prime} / \Delta f\right)$ is about $25(\mathrm{~km} / \mathrm{MHz})$ for the oblique ionogram at 04:45 UTC. Characteristics of the other oblique ionograms before the earthquake showed normal oblique ionograms with a parabolic-shape-trace. The difference between the monthly median of foF2 and the hourly value of foF2 at 04:45 UTC was $+0.85 \mathrm{MHz}$. The ionospheric condition around 04:45 UTC before the earthquake was no disturbances at quarter hourly level on 11 March 2011. A steep slopy-shape-trace before one hour of the earth- 
quake is necessary to investigate further its physical characteristics and the frequency of occurrence before the strong earthquake. The conceptual diagrams classified into three types of (a) parabolic-shape-trace, (b) wavy-shape-trace, and (c) slopy-shape-trace for the "nose" of the relatively medium distance oblique ionograms were shown and discussed. As the oblique ionogram is possible to reveal the ionospheric variations along the propagation pass over the ocean above tectonic plates, it is useful for a study of the preseismic ionospheric anomaly.

\section{Acknowledgements}

The authors are grateful to the World Data Center for Ionosphere and Space Weather at the National Institute of Information and Communications Technology, Japan, for providing the ionograms. The broadband seismic data were provided by the National Research Institute for Earth Science and Disaster Resilience (NIED), Japan. This work was carried out as a joint usage/collaborative research with Shionomisaki Wind Effect Laboratory of the Disaster Prevention Research Institute, Kyoto University. The authors thank Dr. Akira Yoshida for helpful supports at Shionomisaki Wind Effect Laboratory. The authors thank Kwasan Astronomical Observatory, Kyoto University for their assistance. The authors acknowledge OPTAGE Inc. for continuous support regarding the Kyoto University-K-Opticom collaborative research agreement (2017-2020).

\section{Conflicts of Interest}

The authors declare no conflicts of interest regarding the publication of this paper.

\section{References}

[1] Chen, C.H., Saito, A., Lin, C.H., Liu, J.Y., Tsai, H.F., Tsugawa, T., Otsuka, Y., Nishioka, M. and Matsumura, M. (2011) Long-Distance Propagation of Ionospheric Disturbance Generated by the 2011 off the Pacific Coast of Tohoku Earthquake. Earth Planets Space, 63, 881-884. https://doi.org/10.5047/eps.2011.06.026

[2] Saito, A., Tsugawa, T., Otsuka, Y., Nishioka, M., Iyemori, T., Matsumoto, M., Saito, S., Chen, C.H., Goi, Y. and Choosakul, N. (2011) Acoustic Resonance and Plasma Depletion Detected by GPS Total Electron Content Observation after the 2011 off the Pacific Coast of Tohoku Earthquake. Earth Planets Space, 63, 863-867. https://doi.org/10.5047/eps.2011.06.034

[3] Tsugawa, T., Saito, A., Otsuka, Y., Nishioka, M., Maruyama, T., Kato, H., Nagatsuma, T. and Murata, K.T. (2011) Ionospheric Disturbances Detected by GPS Total Electron Content Observation after the Off the Pacific Coast of Tohoku Earthquake. Earth Planets Space, 63, 875-879. https://doi.org/10.5047/eps.2011.06.035

[4] Liu, J.Y., Chen, C.-H., Lin, C.-H., Tsai, H.F., Chen, C.-H. and Kamogawa, M. (2011) Ionospheric Disturbances Triggered by the 11 March 2011 M9.0 Tohoku Earthquake. Journal of Geophysical Research, 116, A06319. https://doi.org/10.1029/2011JA016761

[5] Maruyama, T., Tsugawa, T., Kato, H., Saito, A., Otsuka, Y. and Nishioka, M. (2011) 
Ionospheric Multiple Stratifications and Irregularities Induced by the 2011 off the Pacific Coast of Tohoku Earthquake. Earth Planets Space, 63, 869-873. https://doi.org/10.5047/eps.2011.06.008

[6] Maruyama, T. and Shinagawa, H. (2014) Infrasonic Sounds Excited by Seismic Waves of the 2011 Tohokuoki Earthquake as Visualized in Ionograms. Journal of Geophysical Research Space Physics, 119, 4094-4108. https://doi.org/10.1002/2013JA019707

[7] Nishitani, N., Ogawa, T., Otsuka, Y., Hosokawa, K. and Hori, T. (2011) Propagation of Large Amplitude Ionospheric Disturbances with Velocity Dispersion Observed by the SuperDARN Hokkaido Radar after the 2011 off the Pacific Coast of Tohoku Earthquake. Earth Planets Space, 63, 891-896.

https://doi.org/10.5047/eps.2011.07.003

[8] Ogawa, T., Nishitani, N., Tsugawa, T. and Shiokawa, K. (2012) Giant Ionospheric Disturbances Observed with the SuperDARN Hokkaido HF Radar and GPS Network after the 2011 Tohoku Earthquake. Earth Planets Space, 63, 1295-1307. https://doi.org/10.5047/eps.2012.08.001

[9] Iwata, T. and Umeno, K. (2016) Correlation Analysis for Pre-Seismic Total Electron Content Anomalies around the 2011 Tohoku-Oki Earthquake. Journal of Geophysical Research Space Physics, 121, 8969-8984. https://doi.org/10.1002/2016JA023036

[10] Iwata, T. and Umeno, K. (2017) Preseismic Ionospheric Anomalies Detected before the 2016 Kumamoto Earthquake. Journal of Geophysical Research Space Physics, 122. 3602-3616. https://doi.org/10.1002/2017JA023921

[11] Goto, S., Uchida, R., Igarashi, K., Chen, C.H., Kao, M. and Umeno, K. (2019) Preseismic Ionospheric Anomalies Detected before the 2016 Taiwan Earthquake. Journal of Geophysical Research Space Physics, 124. 9239-9252. https://doi.org/10.1029/2019JA026640

[12] Heki, K. (2011) Ionospheric Electron Enhancement Preceding the 2011 Tohoku-Oki Earthquake. Geophysical Research Letters, 38, L17312. https://doi.org/10.1029/2011GL047908

[13] Heki, K. and Emonoto, Y. (2013) Preseismic Ionospheric Electron Enhancements Revised. Journal of Geophysical Research Space Physics, 118, 6618-6626. https://doi.org/10.1002/jgra.50578

[14] Heki, K. and Enomoto, Y. (2015) $M_{\mathrm{w}}$ Dependence of the Preseismic Ionospheric Electron Enhancements. Journal of Geophysical Research Space Physics, 120, 7006-7020. https://doi.org/10.1002/2015JA021353

[15] Liu, J.Y., Chen, Y.I., Chuo, Y.I. and Tsai, H.F. (2001) Variations of Ionospheric Total Electron Content during the Chi-Chi Earthquake. Geophysical Research Letters, 28, 1383-1386. https://doi.org/10.1029/2000GL012511

[16] Liu, J.Y., Chuo, Y.J., Shan, S.J., Tsai, Y.B., Chen, Y.I., Pulinets, S.A. and Yu, S.B. (2004) Pre-Earthquake Ionospheric Anomalies Registered by Continuous GPS TEC Measurements. Annals of Geophysics, 22, 1585-1593.

https://doi.org/10.5194/angeo-22-1585-2004

[17] Liu, J.Y., Chen, Y.I., Chuo, Y.J. and Chen, C.S. (2006) A Statistical Investigation of Preearthquake Ionospheric Anomaly. Journal of Geophysical Research, 111, A05304. https://doi.org/10.1029/2005JA011333

[18] Liu, J.-Y., Chen, S.-W., Chen, Y.C., Yen, H.Y., Chang, C.-P., Chang, W.Y., Tsai, L.C., Chen, C.H. and Yang, W.H. (2008) Seismo-Ionospheric Precursors of the 26 December 2006 M 7.0 Pingtung Earthquake Doublet. Terrestrial, Atmospheric and Oceanic Sciences, 19, 751-759. https://doi.org/10.3319/TAO.2008.19.6.751(PT) 
[19] Shuanggen, J., Jin, R. and Li., J.H. (2014) Pattern and Evolution of Seismo-Ionospheric Disturbances Following the 2011 Tohoku Earthquakes from GPS Observations. Journal of Geophysical Research Space Physics, 119, 7914-7927. https://doi.org/10.1002/2014JA019825

[20] Piggot, W.R. and Rawer, K. (1978) URSI Handbook of Ionogram Interpretation and Reduction. Report UAG-23A, World Data Center-A, US Dept. of Commerce, 29-34. https://repository.library.noaa.gov/view/noaa/10404

[21] Verhulst, T., Altadill, D., Mielich, J., Reinisch, B., Galkin, I., Mouzakis, A., Belehaki, A., Burešová, D., Stankov, S., Blanch, E. and Kouba, D. (2017) Vertical and Oblique HF Sounding with a Network of Synchronized Ionosondes. Advances in Space Research, 60, 1644-1656. https://doi.org/10.1016/j.asr.2017.06.033

[22] Hocke, K. and Igarashi, K. (2003) Wave-Optical Simulation of the Oblique HF Radio Field. Radio Science, 38, 1039. https://doi.org/10.1029/2002RS002691

[23] Hooke, W.H. (1968) Ionospheric Irregularities Produced by Internal Atmospheric Gravity Waves. Journal of Atmospheric and Solar-Terrestrial Physics, 30, 795-823. https://doi.org/10.1016/S0021-9169(68)80033-9

[24] Heitmann, A.J., Cervera, M.A., Gardiner-Garden, R.S., Holdsworth, D.A., MacKinnon, A.D., Reid, I.M. and Ward, B.D. (2018) Observations and Modeling of Traveling Ionospehric Disturbance Signatures from an Australian Netqork of Oblique Angle-of-Arrival Sounders. Radio Science, 53, 1089-1107. https://doi.org/10.1029/2018RS006613

[25] Yang, S.S., Asano, T. and Hayakawa, M. (2019) Abnormal Gravity Wave Activity in the Stratosphere Prior to the 2016 Kumamoto Earthquake. Journal of Geophysical Research Space Physics, 124, 1410-1425. https://doi.org/10.1029/2018JA026002 